\title{
Effects of Different Rain Parameterizations on the Simulation of Mesoscale Orographic Precipitation
}

\author{
EVELYNE RICHARD AND NADINE CHAUMERLIAC \\ LAMP/OPGC, Université Blaise Pascal, Clermont-Ferrand, France
}

(Manuscript received 17 February 1989, in final form 30 May 1989)

\begin{abstract}
A detailed comparison is made between the results obtained from two microphysical parameterizations capable of simulating cloud and precipitation processes in a mesoscale model. The behavior of each microphysical scheme is first investigated in the context of a mountain wave simulation. Major differences are found in raindrop size distributions as well as in the rates associated with various microphysical processes. An assessment of the accuracy of each scheme is then obtained by comparing model predictions with observational data from well-documented orographically enhanced precipitation episodes in South Wales. The parameterization of Berry and Reinhardt does a better job of reproducing the observed dependency of the precipitation enhancement on the low-level windspeed than does Kessler's.
\end{abstract}

\section{Introduction}

Various recent studies have highlighted the influence of moist processes upon the dynamics of mesoscale circulations wherein feedbacks may occur through diabatic processes as well as precipitation loading (Durran and Klemp 1983; Hsie et al. 1984). Mesoscale models generally treat precipitation processes in a resolvable, explicit manner or by means of a subgrid scale parameterization procedure (a concise description of the relative importance of those two procedures may be found in Zhang et al. 1988). Clearly, microphysical processes must be included in any dynamical model that seeks to replicate the behavior of active weather systems. A major unresolved question, however, is the degree of complexity that must be included in any representation of cloud and precipitation processes. The following discussion only considers the question of resolvable precipitation wherein the microphysical processes within each grid volume are explicitly represented by a set of one or more equations in a complete set of model equations.

On the one hand, very detailed formulations such as those developed for cloud models can be used. As many as 50 to 100 equations are then required to represent growth of cloud droplets to precipitation-sized particles (Berry 1967; Clark and Hall 1983). Such a degree of complexity, however, is impractical for most present day applications using a mesoscale model. On the other hand, microphysical processes can be param-

Corresponding author address: Dr. Evelyne Richard, LAMP/ OPGC, Université Blaise Pascal, 12, avenue des Landais, 63000 Clermont-Ferrand, France. eterized with a bulk representation. Limiting the problem to the consideration of only warm phase processes, liquid water is subdivided into two classes: cloud water and rainwater. This type of parameterization based upon Kessler's work (1969) has been widely used (Cotton 1972; Orville and Kopp 1977; Rutledge and Hobbs 1983). The calculation of microphysical sources and sinks requires some assumption of the raindrop size distribution. Kessler type parameterizations make use of an inverse exponential function, known as the Marshall-Palmer distribution (Marshall and Palmer 1948).

Between the many equation formulation and the single equation formulation of Kessler, a compromise was proposed by Berry and Reinhardt (1974a,b), who derived a new parameterization from the stochastic coalescence equation, less empirical than Kessler's and yet nearly as convenient as Kessler's to implement in a mesoscale model (Nickerson et al. 1986). Liquid water is subdivided between cloud water and rainwater as in Kessler's scheme, but an extra predictive equation is added for the raindrop number concentration, thereby providing an additional degree of freedom. Selfcollection and partial evaporation may now be taken into account. In this formulation raindrops are assumed to conform to a log-normal distribution.

This paper examines both the Kessler parameterization and the Berry and Reinhardt parameterization with the overall objective of determining their respective abilities to simulate the details of the microphysics occurring in precipitation processes within orographically forced cloud systems.

A brief description of both parameterizations is given, including prognostic equations, raindrop distri- 
bution functions (section 2) as well as microphysical processes (section 3 ). In section 4 , model results for the two microphysical schemes are systematically compared in the context of an idealized case of a moist mountain wave. This comparison is then generalized, in section 5, to various episodes of orographically enhanced precipitation associated with the feeder-seeder mechanism, for which observational data are available to compare with model predictions.

\section{Predictive equations and raindrop distributions}

In this section, the two microphysical parameterizations of Kessler (K) and Berry and Reinhardt (BR) are briefly summarized. In both cases, the cloud water mixing ratio $q_{c w}$ is diagnosed from the prognostic variable $q$, which is the sum of the water vapor mixing ratio $q_{v}$ and the cloud water mixing ratio $q_{c w}$. In case of supersaturation, $q_{v}$ is set equal to the saturated vapor mixing ratio $\left(q_{v s}\right)$ and the excess vapor is converted into cloud water.

In the $\mathrm{K}$ parameterization, rainwater is predicted solely by its mixing ratio $q_{r w}$ whereas the BR parameterization is based upon the prediction of both mixing ratio and raindrop total number concentration $N_{r w}$. This leads to the following set of equations for $\mathrm{K}$ :

$$
\begin{aligned}
\frac{d q}{d t} & =-A U(Q)-A C(Q)+E V(Q)+F_{r}(Q), \\
\frac{d q_{r w}}{d t} & =A U(Q)+A C(Q)+S E(Q)-E V(Q),
\end{aligned}
$$

and for BR:

$$
\begin{aligned}
\frac{d q}{d t} & =-A U(Q)-A C(Q)+E V(Q)+F_{r}(Q), \\
\frac{d q_{r w}}{d t} & =A U(Q)+A C(Q)+S E(Q)-E V(Q), \\
\frac{d N_{r w}}{d t} & =A U(N)+S E(N)-S C(N)-E V(N) .
\end{aligned}
$$

The microphysical processes taken into account are autoconversion $(A U)$, accretion $(A C)$, evaporation $(E V)$, sedimentation $(S E)$ and self-collection $(S C)$. It should be noticed that self-collection (coalescence of raindrops among themselves) only arises in BR's parameterization. Here $F_{r}(Q)$ designates the turbulent mixing term, and $Q$ and $N$ refer to mixing ratio and to number concentration, respectively.

Both parameterizations make use of raindrop distribution functions which are: 1) Marshall-Palmer for the K parameterization, and 2) log-normal distribution for the BR parameterization. For the first case, the number of raindrops whose diameter lies in the interval $D$ to $D+d D$ is given by

$$
N(D) d D=N_{0} \exp (-\lambda D) d D:
$$

This formulation originally derived by MarshallPalmer (1948) has been widely used. Observations from Waldvogel (1974) for different types of rain show a range of values for $N_{0}$, from $0.410^{7} \mathrm{~m}^{-4}$ to $3.510^{7}$ $\mathrm{m}^{-4}$. The total mass of precipitation per unit volume is obtained by multiplying the distribution given in (6) by the mass of one raindrop of diameter $D$ and by integrating over all diameters, i.e.,

$$
\rho_{a} q_{r w}=\int_{0}^{\infty} \frac{\pi}{6} \rho_{w} D^{3} N_{0} \exp (-\lambda D) d D=\frac{\pi \rho_{w} N_{0}}{\lambda^{4}},
$$

where $\rho_{a}, \rho_{w}$ are air and water densities respectively. For the log-normal distribution, the number of raindrops in the diameter interval $D$ to $D+d D$ is expressed as

$$
N(D) d D=\frac{N_{r w}}{\sqrt{2 \pi} \sigma_{r} D} \exp \left[-\frac{1}{2 \sigma_{r}^{2}} \ln ^{2}\left(\frac{D}{D_{0 r}}\right)\right] d D,
$$

where $D_{0 r}$ is the median size diameter and $\sigma_{r}$ the standard geometric deviation which is a measure of the breadth of the spectrum. The rainwater content is then given by

$$
\begin{aligned}
\rho_{a} q_{r w} & =\int_{0}^{\infty} \frac{\pi}{6} \rho_{w} D^{3} N(D) d D \\
& =N_{r w} \frac{\pi}{6} \rho_{w} D_{0 r}^{3} \exp \left(\frac{9}{2} \sigma_{r}^{2}\right) .
\end{aligned}
$$

In both cases, there are more parameters in the distributions than predictive variables, therefore for each distribution, one of these unknown parameters must be specified. The effects of varying these parameters are illustrated in Fig. 1, which presents mass density functions for a given rainwater content of $0.5 \mathrm{~g} \mathrm{~m}^{-3}$, as a function of raindrop diameter. Figure la corresponds to the Marshall-Palmer distribution for various values of $N_{0}$; Fig. $1 \mathrm{~b}$ corresponds to the log-normal distribution for three values of $\sigma_{r}$ and a given number concentration $N_{r w}$. The variation of $N_{0}$ over the whole range of measured values has little effect on the mass density function. A slight shift towards larger diameters is observed when $N_{0}$ is decreased but the peak value and the shape of the curves remain the same. Therefore, in the following, $N_{0}$ will be set equal to $10^{7} \mathrm{~m}^{-4}$. A quite different behavior is found in Fig. 1b. The mass density function is much more sensitive to changes in $\sigma_{r}$. A decrease in $\sigma_{r}$ both reduces the peak value and broadens the spectrum. The value $\sigma_{r}=0.547$ is then retained providing the log-normal distribution with the most similar spectrum both in shape and amplitude to the Marshall-Palmer distribution. In the Kessler parameterization, it is now possible to compute the other parameter $\lambda$ as a function of $N_{0}$ and $q_{r w}$ [cf. Eq. (7)]. In the same way, $D_{0 r}$ in the BR parameterization can be expressed as a function of $\sigma_{r}, q_{r w}$ and $N_{r w}$ [cf. Eq. (9)]. 

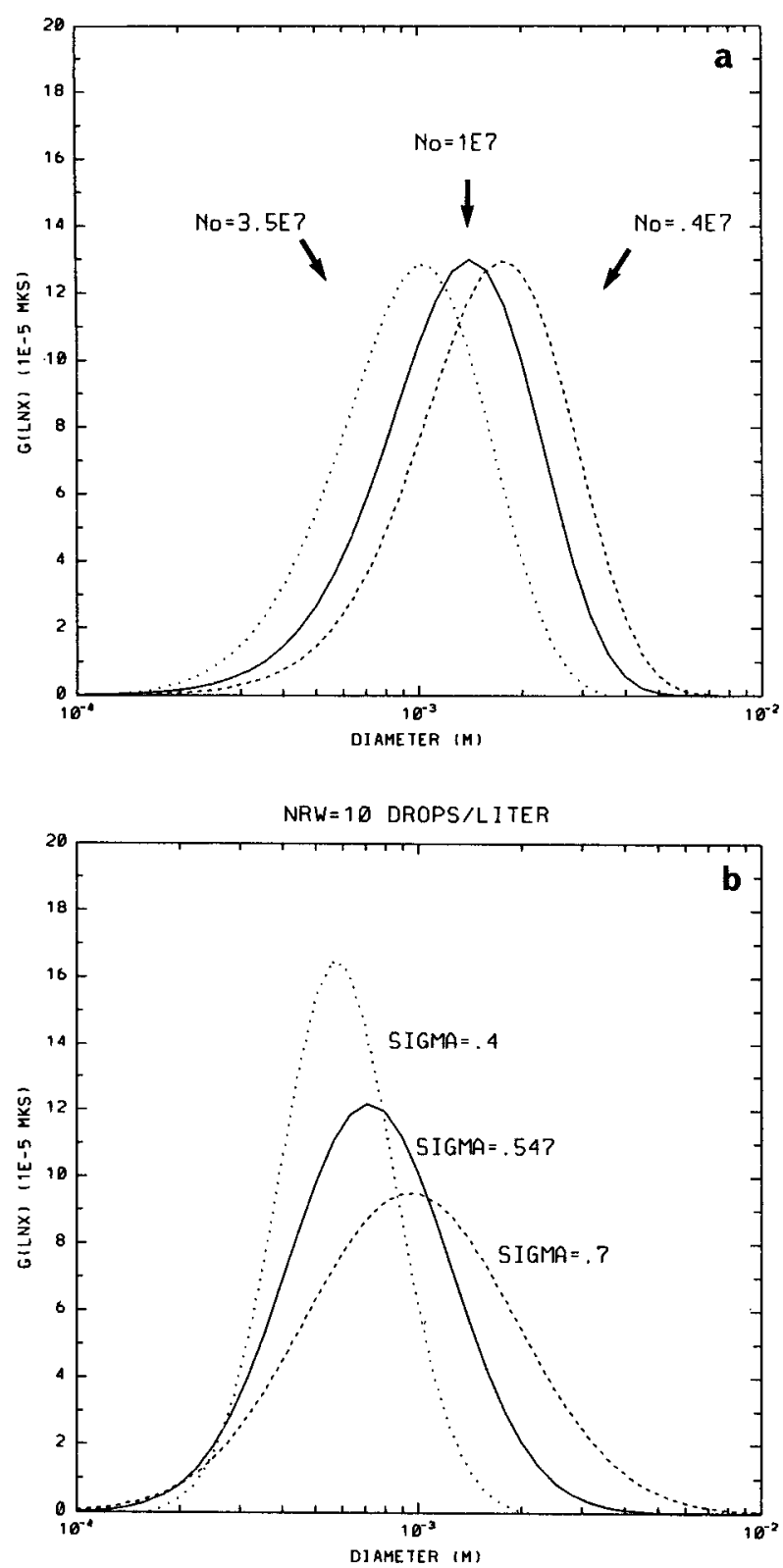

FIG. 1. Mass density functions for a given rainwater content of $0.5 \mathrm{~g} \mathrm{~m}^{-3}$ as a function of raindrop diameter: (a) for Marshall-Palmer distribution for three values of $N_{0}$, expressed in $\mathrm{m}^{-4}$, (b) for $\log$ normal distribution for three values of $\sigma_{r}$ and $N_{r w}=10$ drops per liter.

One of the major advantages in the BR parameterization is the prediction of $N_{r w}$, which allows much more flexibility in the representation of the raindrop spectrum. As an example, for a fixed value of the rainwater content, log-normal mass density functions have been drawn in Fig. 2 for three predicted values of the number concentration and compared with the corresponding function for Marshall-Palmer. Depending on the predicted value of the concentration, the BR spectrum is centered on small diameter $(500 \mu \mathrm{m})$ or on large diameter $(1000 \mu \mathrm{m})$, while the $\mathrm{K}$ spectrum remains centered on the same (large) diameter. In the case of Kessler, the shift of the spectrum towards larger diameter can be achieved only by increasing the rainwater mixing ratio, while in the case of BR it can also result from decreasing the number concentration. Therefore, the prediction of the number concentration combined with a log-normal distribution brings an additional degree of freedom which provides more detailed information about the raindrop size spectrum and facilitates the representation of the physical processes which control the evolution of the spectrum (Feingold and Levin 1986).

\section{Microphysical processes}

\section{a. Autoconversion}

The sole rainwater initiation mechanism is the autoconversion process. The autoconversion rates for the two parameterizations are written as:

for Kessler,

$$
A U_{\mathrm{K}}(Q)= \begin{cases}\frac{k_{1}}{\rho_{a}}\left(\rho_{a} q_{c w}-a\right) & \text { if } \rho_{a} q_{c w}>a \\ 0 & \text { if not; }\end{cases}
$$

for $B R$,

$$
\begin{aligned}
& A U_{\mathrm{BR}}(Q)=\alpha\left(\overline{D_{c w}}, \sigma_{c}\right)\left(\rho_{a} q_{c w}^{2}\right) \\
& A U_{\mathrm{BR}}(N)=3.510^{9} \alpha\left(\overline{D_{c w}}, \sigma_{c}\right)\left(\rho_{a} q_{c w}\right)^{2} .
\end{aligned}
$$

The Kessler rate relies on intuitive considerations: the

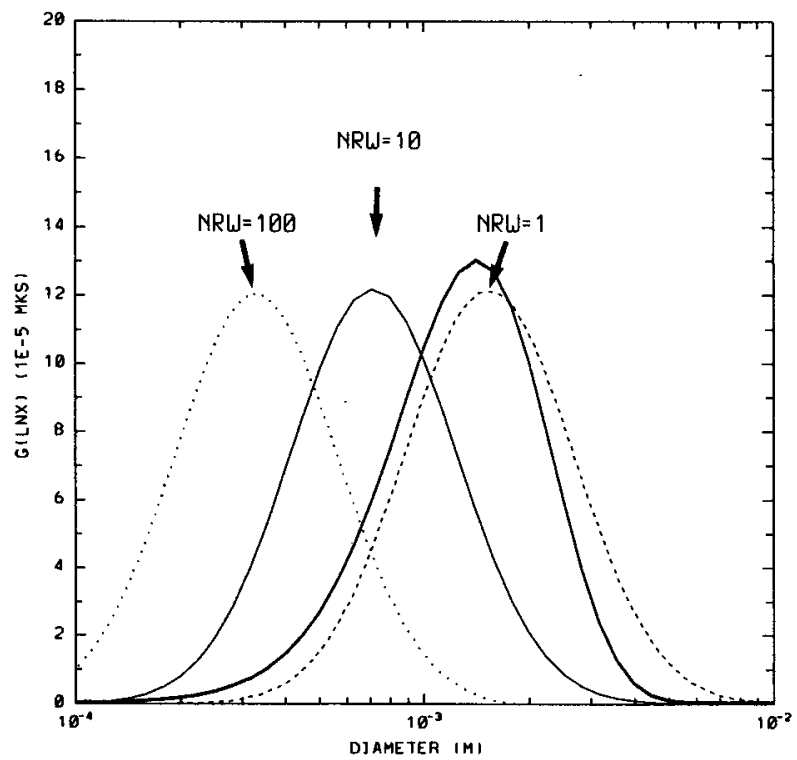

FIG. 2. Mass density functions for a given rainwater content of $0.5 \mathrm{~g} \mathrm{~m}^{-3}$ obtained with the log-normal distribution for $\sigma_{r}=0.547$ and three predicted values of $N_{n w}$ in drops per liter (thin lines) and with the Marshall-Palmer distribution for $N_{0}=10^{7} \mathrm{~m}^{-4}$ (thick line). 
autoconversion rate increases linearly with the cloud water content but cloud conversion does not occur below a threshold value $a$. Berry and Reinhardt's formulation is based upon results from solutions of the stochastic coalescence equations using a detailed microphysical model employing 72 discrete size categories. The coefficient $\alpha$ depends on cloud spectrum features:

$$
\begin{aligned}
\alpha\left(\overline{D_{c w}}, \sigma_{c}\right)= & 0.0067\left[10^{16} \overline{N_{c w}}-4 / 3 \sqrt{\operatorname{var} x}-2.7\right] \\
& \times\left[10^{4}\left(\overline{N_{c w}}-1 \sqrt{\operatorname{var} x}\right)^{1 / 3}-1.2\right],
\end{aligned}
$$

where

$$
\begin{aligned}
\operatorname{var} x & =\exp \left(9 \sigma_{c}^{2}\right)-1 \\
\bar{N}_{c w}-1 & =\frac{\rho_{a} q_{c w}}{N_{c w}}=\frac{\pi}{6} \rho_{w} D_{0 c}^{3} \exp \left(\frac{9}{2} \sigma_{c}^{2}\right),
\end{aligned}
$$

assuming that cloud droplets are distributed according to a $\log$-normal function of parameters $\sigma_{c}, D_{0 c}$. Adjusting the $\alpha$ coefficient provides us with the flexibility necessary to simulate the extreme differences in the colloidal stability of clouds formed in various air masses. A maritime cloud spectrum will lead to a much greater value of $\alpha$ than a continental one. And in contrast to Kessler's formulation, BR's formulation permits autoconversion in the early stages of cloud droplet collection, thereby allowing for the production of rainwater even for low cloud water contents.

Figure 3 presents autoconversion rates as a function of the cloud water content. For the Kessler parameterization, the parameters $k_{1}$ and $a$ are commonly chosen equal to $10^{-3} \mathrm{~s}^{-1}$ and $0.5 \mathrm{~g} \mathrm{~m}^{-3}$ respectively. In the case of $\mathrm{BR}$, two curves are plotted corresponding to $\alpha(35 \mu \mathrm{m}, 0.2775)=0.66(\mathrm{BR} 1)$ and $\alpha(27.5 \mu \mathrm{m}$, $0.2775)=0.15(B R 2)$. These two values, both typical

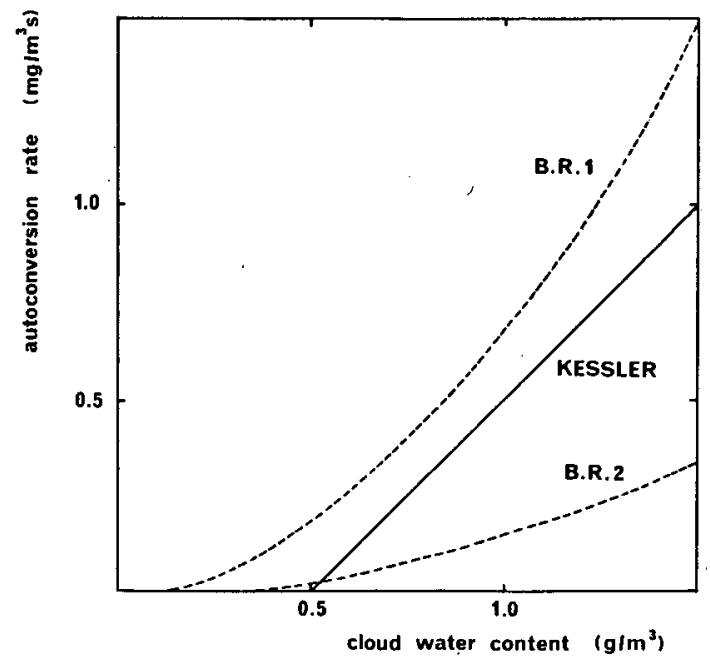

FIG. 3. Autoconversion rates as a function of cloud water content for Kessler and for two values of the autoconversion coefficient of Berry and Reinhardt's parameterization. of a maritime cloud spectrum, result in the two BR autoconversion rates bracketing the Kessler rate.

\section{b. Accretion and sedimentation}

Once embryonic precipitation particles are formed, rainwater mixing ratio growth occurs primarily by accretion of cloud water in the form:

for Kessler,

$A C_{\mathrm{K}}(Q)=0.2935 N_{0}^{1 / 8}\left(\frac{\rho_{0}}{\rho_{a}}\right)^{1 / 2} q_{c w}\left(\rho_{a} q_{r w}\right)^{7 / 8}$

and for BR,

$$
\begin{aligned}
A C_{\mathrm{BR}}(Q)=\frac{3 \rho_{a} q_{r w} q_{c w}}{2 \rho_{w} D_{g r}} & \gamma_{c}^{2}\left(D_{g r}, \overline{D_{c w}}\right) \\
& \times\left[V\left(D_{g r}\right)-V\left(\overline{D_{c w}}\right)\right],
\end{aligned}
$$

where $D_{g r}$ is the predominant diameter of the rainwater distribution, $\overline{D_{c w}}$ is the mean diameter of the cloud water distribution. Here $\gamma_{c}^{2}\left(D, D^{\prime}\right)$ is the collision efficiency between drops of diameters $D$ and $D^{\prime}$, and $V(D)$, the terminal fall velocity for a drop of diameter $D$, is expressed in MKS as:

for Kessler,

$$
V(D)=130\left(\frac{\rho_{0}}{\rho_{a}}\right)^{0.5} D^{0.5}
$$

and for $\mathrm{BR}$,

$$
V(D)=\frac{\eta \mathrm{Re}}{\rho_{a} D} .
$$

The reader is referred to the list of symbols for further details. Equation (16) is used to derive Eq. (14) as given in Kessler (1969). Equation (17) is taken from Berry and Pranger (1974). It is important to note that the BR accretion rate is parameterized as a function of the collection kernal [Eq. (15)], eliminating the need to evaluate arbitrary coefficients, as in the Kessler case.

In contrast to the formulations for the accretion terms, the sedimentation process is formulated in the same way for the two parameterizations as

$$
\begin{aligned}
S E(Q) & =\frac{\partial}{\partial z}\left(F_{q}\right) \\
& =\frac{\partial}{\partial z} \int_{0}^{\infty} N(D) V(D) \frac{\pi}{6} \frac{\rho_{w}}{\rho_{a}} D^{3} d D,
\end{aligned}
$$

where $F_{q}$ represents the sedimentation flux. The difference between the BR and the $K$ expressions just results from different formulations of terminal velocities and distribution functions.

In Fig. 4a, accretion rates divided by the cloud water content are shown as a function of the rainwater mixing ratio in the $K$ case and in the BR case for three values of the total number concentration. The accretion pro- 

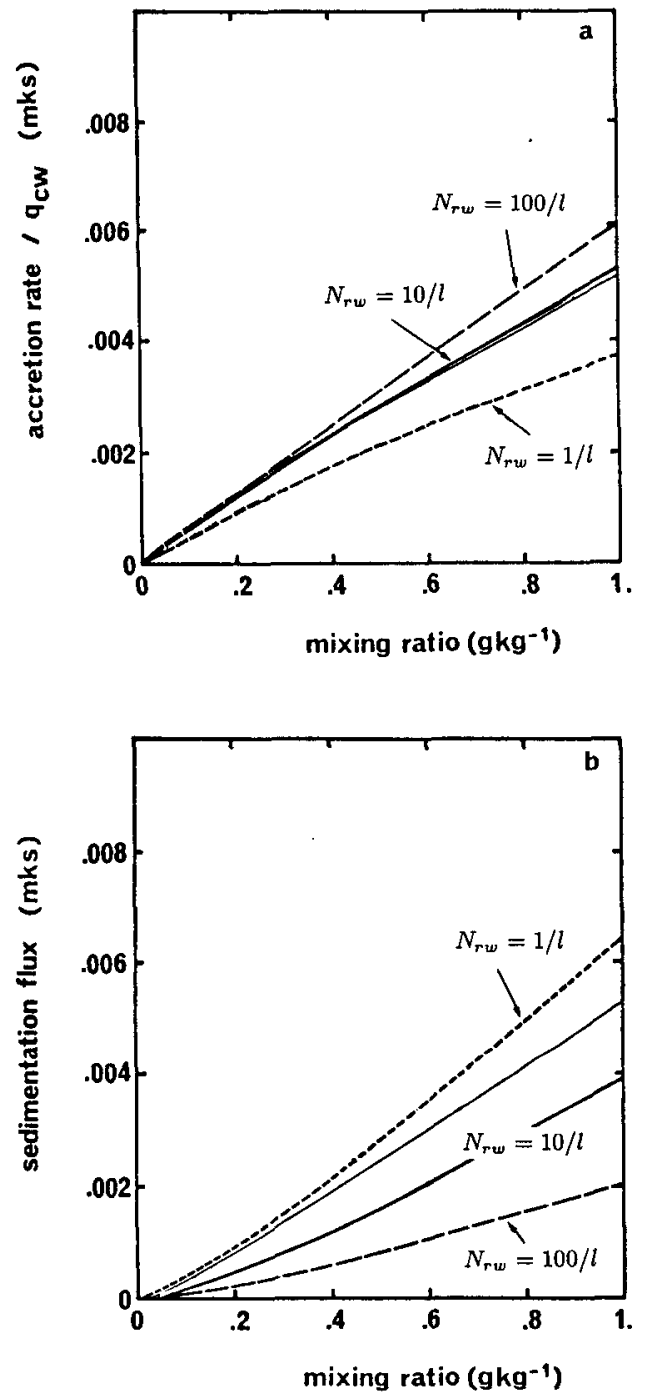

Fig. 4. (a) Accretion rates divided by the cloud water mixing ratio as a function of rainwater mixing ratio. (b) Sedimentation fluxes as a function of rainwater mixing ratio in the Kessler case (thin line) and in the Berry and Reinhardt case for the three values of $N_{r w}$ (thick lines).

cess, as formulated by BR, is more efficient when the rainwater content is carried by smaller raindrops, i.e., higher concentrations. The accretion rate obtained by 10 drops/liter in BR closely matches the Kessler curve. Figure $4 \mathrm{~b}$ shows the sedimentation fluxes as a function of the rainwater mixing ratio. This time, the sedimentation process is more efficient when the rainwater content is carried by larger raindrops. The Kessler curve is located between the 1 and 10 drops/liter BR curves.

\section{c. Evaporation}

Similarly, one can estimate the rate of change due to evaporation of raindrops. Kessler, using experimental data from Gunn and Kinzer (1949), found

$$
E V_{\mathrm{K}}(Q)=0.1710^{-3} N_{0}^{0.35}\left(\rho_{a} q_{r w}\right)^{0.65}\left(q_{v s}-q_{v}\right)
$$

In the case of $B R$, the evaporation rate is obtained from a more complete theoretical calculation including ventilation effects, pressure and temperature dependency as in Pruppacher and Klett (1978). It can be written as

$$
\begin{aligned}
E V_{\mathrm{BR}}(Q)= & \frac{2 \pi}{A_{3}} N_{r w}\left[-4.3310^{5}{\overline{D_{r w}}}^{3}\right. \\
& +5.3110^{3}{\overline{D_{r w}}}^{2} \exp \left(-\sigma_{r}^{2}\right) \\
& \left.+0.572 \overline{D_{r w}} \exp \left(-\sigma_{r}^{2}\right)\right] \frac{\left(q_{v s}-q_{v}\right)}{\rho_{a} q_{v s}} .
\end{aligned}
$$

In BR, an additional term is considered on the concentration in order to take into account the number of raindrops which disappear completely by evaporation during each time step $\Delta t$. The raindrops evaporate completely as soon as they have a diameter smaller than a critical value $D_{\text {crit }}$ calculated by

$$
\int_{D_{\text {crit }}}^{0} D d D=\int_{t}^{t+\Delta t} \frac{4}{A_{3} \rho_{w}}\left(1-\frac{q_{v}}{q_{v s}}\right) d t
$$

This leads to

$$
E V_{\mathrm{BR}}(N)=\int_{0}^{D_{\text {crit }}} N(D) d D .
$$

Figure 5 shows $E V_{\mathrm{K}}(Q)$ and $E V_{\mathrm{BR}}(Q)$ divided by $\left(q_{v}\right.$ $-q_{v s}$ ) for three values of $N_{r w}$ at two different pressure levels. The BR evaporation rate is highly sensitive to the raindrop concentration and the evaporation of small raindrops is favored. The Kessler formulation does not allow any dependency of the evaporation rate on droplet size and provides at the ground an evaporation rate which is between these obtained from $B R$ for $N_{r w}=1$ and 10 drops/liter. Moreover, the Kessler evaporation rate does not vary with altitude, whereas BR's rates are about twice as large at $700 \mathrm{mb}$ as they are at $1000 \mathrm{mb}$.

\section{Mountain wave simulations}

Simulations have been performed with a two-dimensional version of the model (Nickerson et al. 1986) over a horizontal domain of $430 \mathrm{~km}$ with a grid mesh of $10 \mathrm{~km}$. The vertical domain extends from the ground to $100 \mathrm{mb}$ and is discretized into 15 equally spaced levels in the vertical coordinate $\nu$ (where $\nu$ is a modified $\sigma$ vertical coordinate). Lateral boundary conditions are of the Davies type (Davies 1983). At the upper boundary, a top absorbing layer occupies the first five vertical levels. The simulation duration is $6 \mathrm{~h}$ with a time step of $10 \mathrm{~s}$. The planetary boundary layer is parameterized according to O'Brien (1970) with a constant depth of $1 \mathrm{~km}$. 

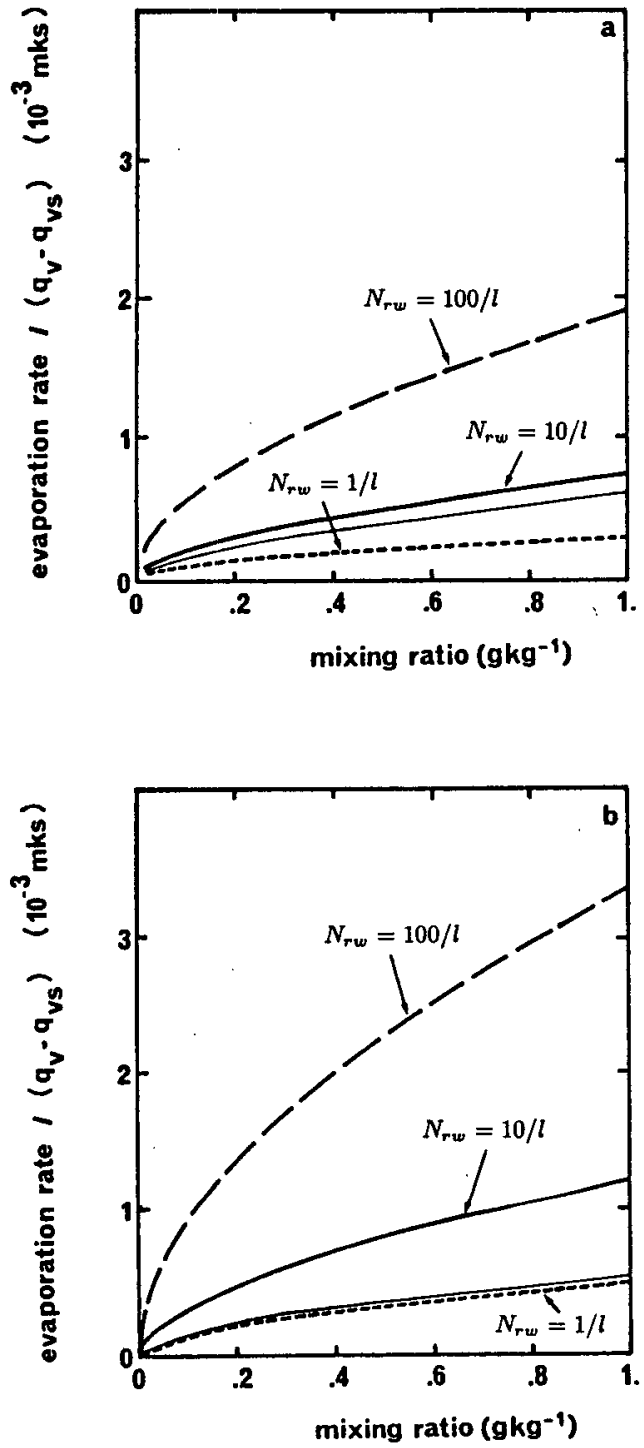

FIG. 5. Evaporation rates divided by $q_{v}-q_{v s}$ as a function of rainwater mixing ratio (Kessler formulation in thin line and Berry and Reinhardt formulation for three values of $N_{m w}$ in thick lines). (a) at $1000 \mathrm{mb},(\mathrm{b})$ at $700 \mathrm{mb}$.

A meteorological scenario of a mountain wave has been selected in order to provide a well-defined forcing mechanism as well as a dynamical and thermodynamical consistent setting for the production of clouds and precipitation (Durran and Klemp 1983; Chaumerliac et al. 1987). The model is run over an idealized bellshaped mountain, $1 \mathrm{~km}$ high and $20 \mathrm{~km}$ in halfwidth. The initial atmosphere consists in a layer of constant lapse rate with $80 \%$ relative humidity up to $250 \mathrm{mb}$, which is topped by a dry isothermal layer. The initial horizontal windspeed is $20 \mathrm{~m} \mathrm{~s}^{-1}$.

For this orographic rain situation, results obtained both from $\mathrm{K}$ and $\mathrm{BR}$ are systematically compared. The BR results are presented for the two values of the au- toconversion coefficient defined in section 3a. First, results from complete runs, including all of the processes are studied. Then, the role of each process is investigated individually.

In Fig. 6, vertical cross sections of cloud water mixing ratios, rainwater mixing ratios and precipitation rates have been reported for $\mathrm{K}, \mathrm{BR} 1$ and BR2. Cloud water fields (Fig. 6a) are comparable for $\mathrm{K}$ and $\mathrm{BR} 2$, whereas cloud water mixing ratios obtained with $\mathrm{BR} 1$ are weaker due to a more efficient conversion from cloud to rain. The precipitation rates of K and BR2 (Fig. 6c) are also comparable in intensity but differ slightly in their spatial extent. Surprisingly, the corresponding rainwater mixing ratios (Fig. 6b) are quite different. BR2 produces much larger rainwater mixing ratios than K. Further insight may be obtained from Fig. 7, which shows mass density functions for K, BR 1 and BR2 for various model grid points in the vicinity of the mountain. For all the selected grid points, the Kessler mass density functions are systematically centered over larger diameters. Such differences in raindrop sizes provide a rationale for the interpretation of the differing behavior of the BR and K schemes. In the Kessler scheme, large raindrops precipitate with greater terminal velocity than BR raindrops, so that rainwater mixing ratio is depleted much faster. Another effect directly related to raindrop size is the downwind spreading of the precipitating zone in the case of BR. The BR raindrops, which are smaller than the Kessler raindrops, are more sensitive to wind drift effects.

In order to emphasize the differences inherent in each microphysical process, we have carried out a series of simplified runs: in run A, only autoconversion and sedimentation are considered, then successively selfcollection (run B), accretion (run C) and rain evaporation (complete run) are added.

In Fig. 8, vertical cross sections of the rainwater mixing ratios and precipitation rates are represented for $\mathrm{K}, \mathrm{BR} 1$ and BR2 in case of run A. Recalling that the Kessler autoconversion rates were intermediate between those of BR1 and BR2 (Fig. 3), Kessler should give more rain than $B R 2$ and less than BR1. As expected, we did find that BR1 leads to much higher rainwater mixing ratios and precipitation rates than BR2. For Kessler, however, the rainwater mixing ratio is weaker than for BR2, while the precipitation rate is greater than for BR1. This behavior should be attributed, as already mentioned for the complete run, to the size of the raindrops which are larger and have a greater terminal velocity in $\mathrm{K}$ than in BR1 and in BR2. In other words, for the Kessler scheme, the autoconversion source is overwhelmed by the sedimentation sink.

Results from run B taking into account self-collection are shown in Fig. 9, using the same format as Fig. 8. This process is not included in the Kessler parameterization and Figs. $9 a$ and $9 b$ merely duplicate Figs. $8 \mathrm{a}$ and $8 \mathrm{~b}$. Comparing results from run $\mathrm{A}$ and run $\mathrm{B}$, 
KESSLER

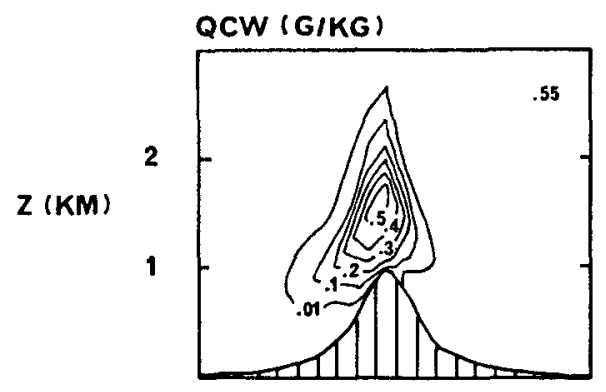

QRW (G/KG)

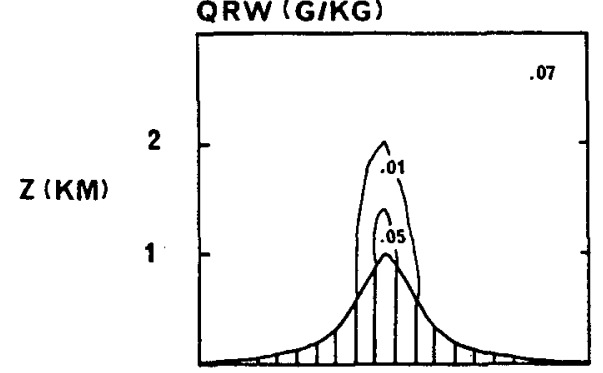

$P(M M / H)$

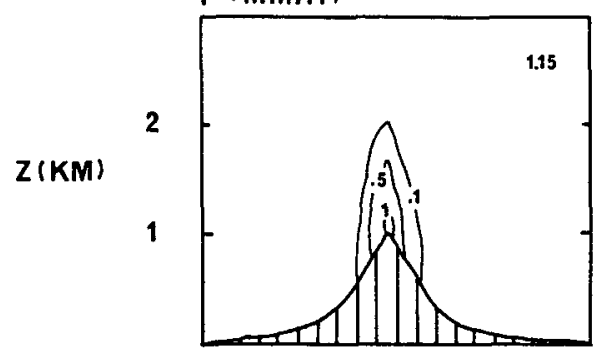

B.R. 1

QCW (GIKG)

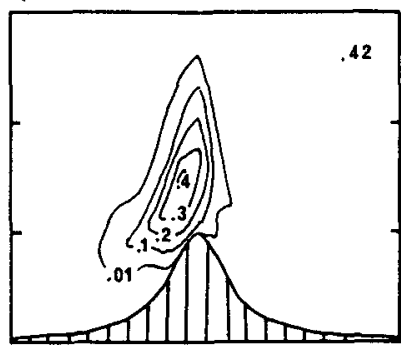

QRW (GIKG)

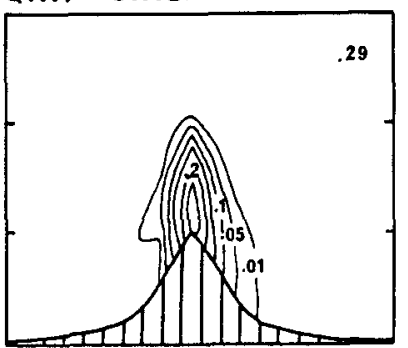

$P(M M I H)$

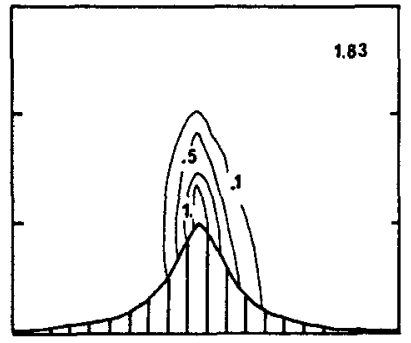

B.R. 2

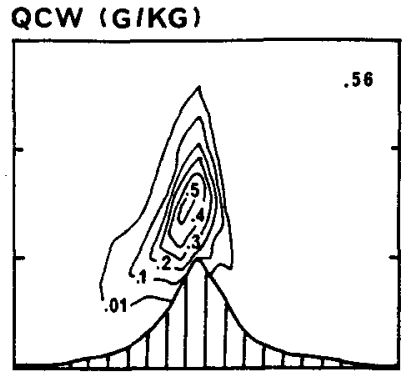

QRW (GIKG)

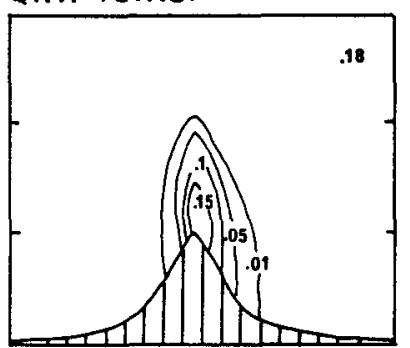

P (MMIH)

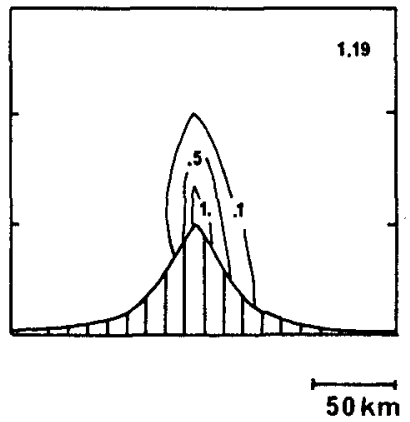

a

FIG. 6. Vertical cross sections of cloud water mixing ratios, rainwater mixing ratios and precipitation rates for K, BR1 and BR2. Maximum values are given in the upper right corner of each figure.

one notices that by including self-collection, the downwind extent of the precipitating zone has been reduced in the case of BR1. Rainwater mixing ratios have about the same intensity in runs A and B, however, since the self-collection process only acts on number concentrations. The precipitation rate changes very little in BR2, while it increases about $30 \%$ in BR1. When self-collection is acting efficiently, as in $\mathrm{BR}^{\prime} 1$, the raindrop spectrum is shifted towards larger diameters. Consequently, these larger raindrops are less sensitive to advection and also induce a stronger precipitation rate. In the case of BR2, self-collection has little effect because the BR2 raindrop spectrum does not comprise enough large raindrops to initiate the self-collection process.

Moving to Fig. 10, which presents the results from run $\mathrm{C}$, accretion is now introduced. A global increase of rainwater mixing ratios and of precipitation rates is found for all the parameterizations (note that isocontour values are not the same as shown previously). This increase from runs $B$ and $C$ is achieved in various proportions: for instance, the precipitation rate increases by a factor of 2 for $\mathrm{K}$, a factor of 5 for BR 1 and a factor of 12 for BR2. This hierarchy in the efficiency of the accretion process comes directly from the fact that smaller droplets, which are more numerous lead to higher accretion rates as shown in Fig. 4. Consequently, the relative importance of the three precipitation rates changes significantly; the $B R$ precipitation rates that are smaller than the Kessler rates in run $B$ become larger as soon as the accretion process is introduced. Also, the spatial extent of the rainwater fields downwind from the mountain top is considerably reduced in run C. By means of the accretion mechanism, 


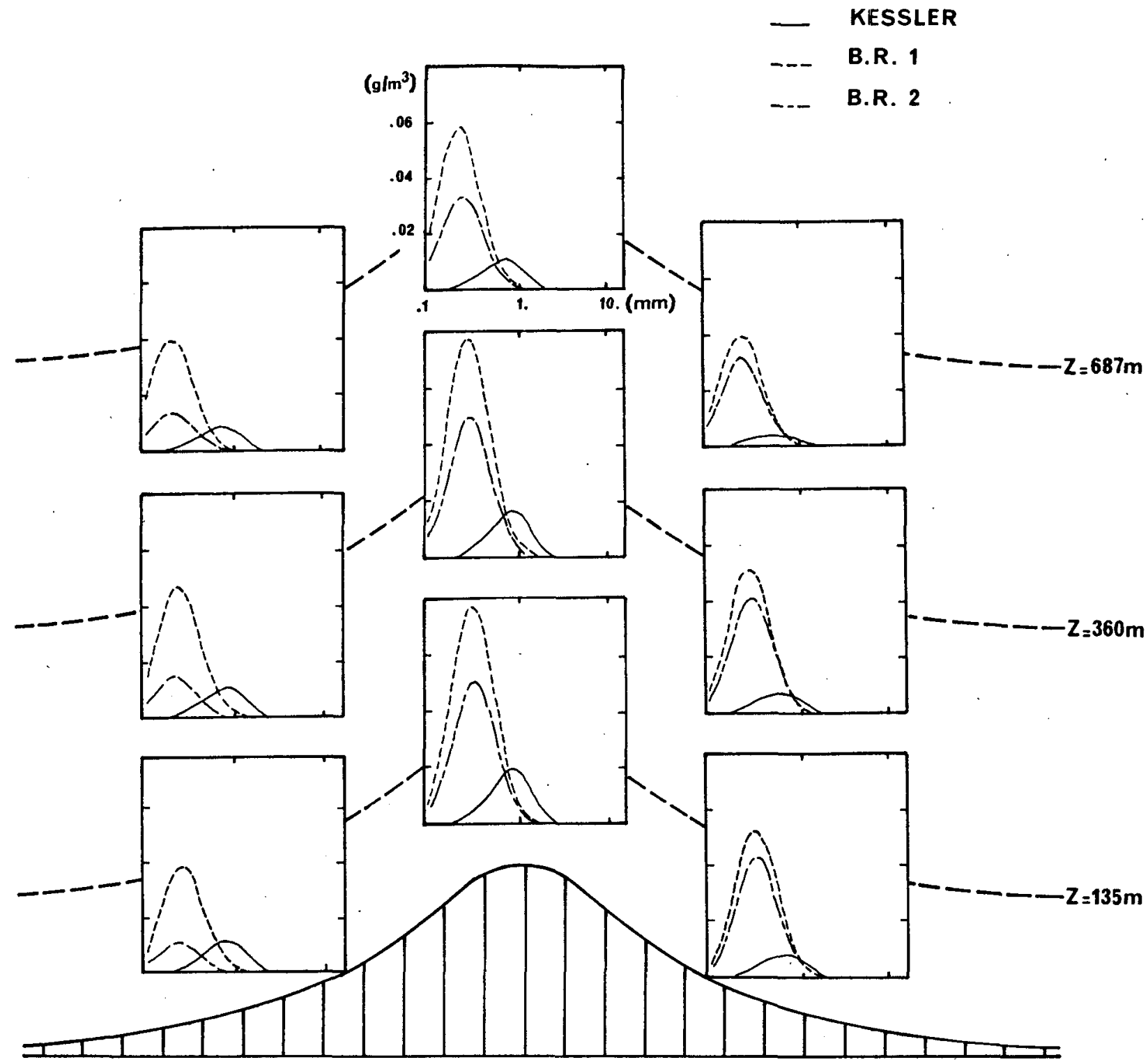

FIG. 7. Mass density functions for raindrops, obtained with $K, B R 1$ and $B R 2$ for three grid points located at mountain top, upwind and downwind from mountain top and for three vertical levels in the model.

raindrop spectra shifted towards larger diameters again make the raindrops less sensitive to horizontal advection.

The last process to be considered is evaporation. Comparing Fig. 10 with Fig. 6, only slight modifications in rainwater mixing ratios and precipitation rate intensities are observed. The main difference between the two figures is the reduction of the downwind spreading for the BR rainwater fields. In the Kessler case, the precipitating zone is not modified through evaporation because most of the precipitation occurs within the saturated area.

These mountain wave simulations give additional insight into the differences previously discussed re- garding raindrop size distribution and microphysical rate expressions. Numerical results permit the establishment of a hierarchy between the various microphysical processes. Sedimentation and accretion, both size-dependent processes, are dominant in determining rainfall production in the two parameterizations; however, their relative contribution differs notably between the two schemes. Other processes like self-collection and evaporation do not quantitatively affect rainwater fields but play a significant role in BR cases by reducing the downwind extent of the precipitating area.

After taking note of these preliminary conclusions obtained for the idealized mountain wave situation and the need for a concluding study involving real data, it 
KESSLER
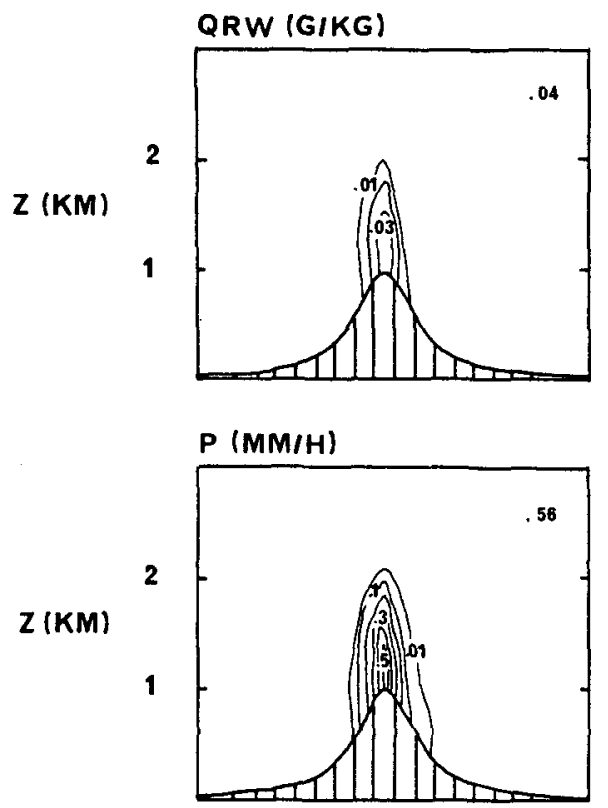

B.R. 1

QRW (GIKG)

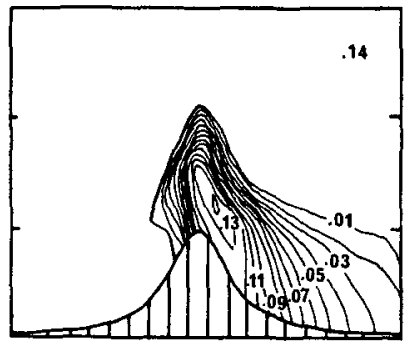

$P(\mathrm{MM} / \mathrm{H})$

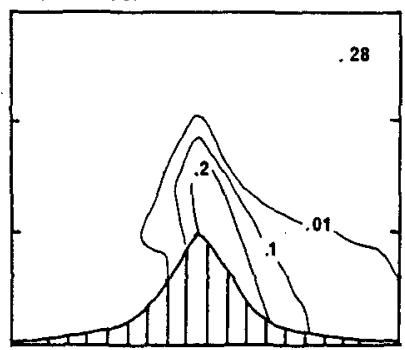

B.R. 2

QRW (G/KG)

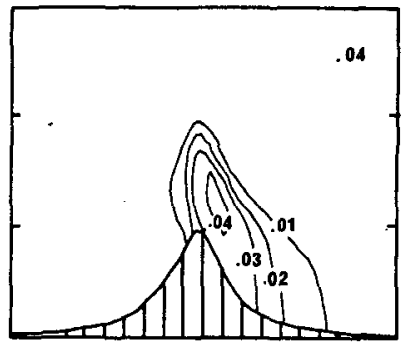

a

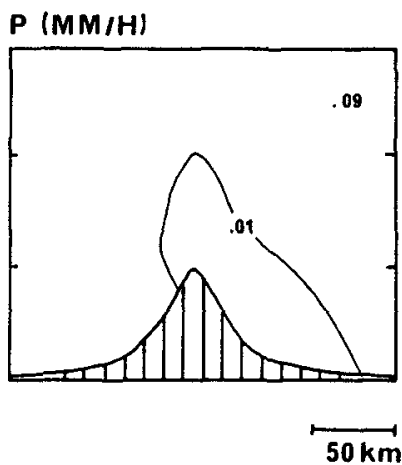

FIG. 8. Vertical cross sections of rainwater mixing ratios and precipitation rates for $K, B R 1$ and $B R 2$, obtained for run $A$. Maximum values are given in the upper right corner of each figure.

KESSLER
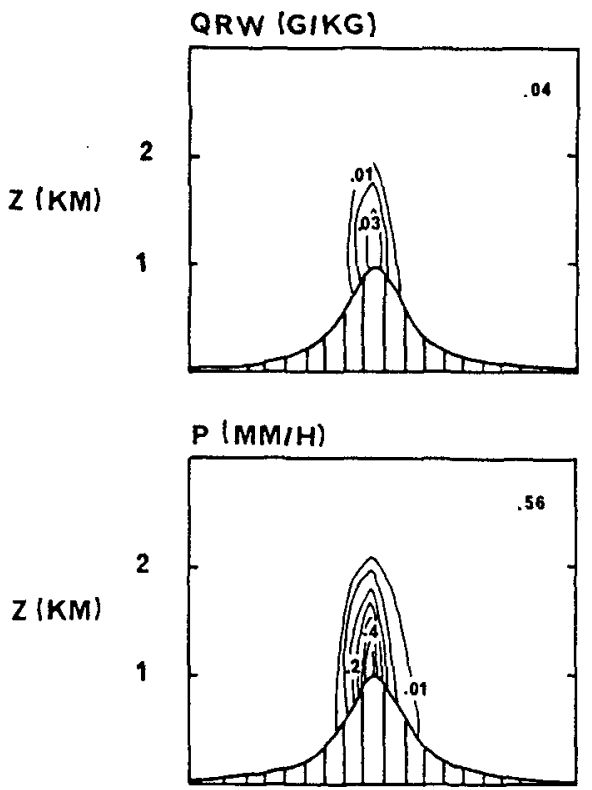

B.R.1

QRW (GIKG)

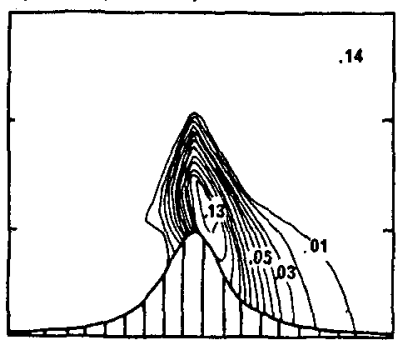

P (MMIH)

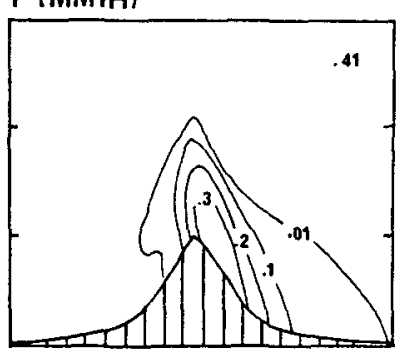

Fig. 9. As in Fig. 8 except for run B.
B.R. 2

QRW (GIKG)

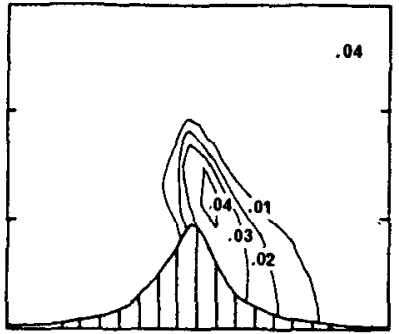

$P(M M / H)$

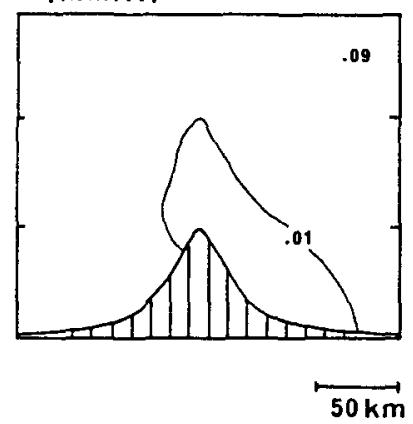

a

b 
KESSLER

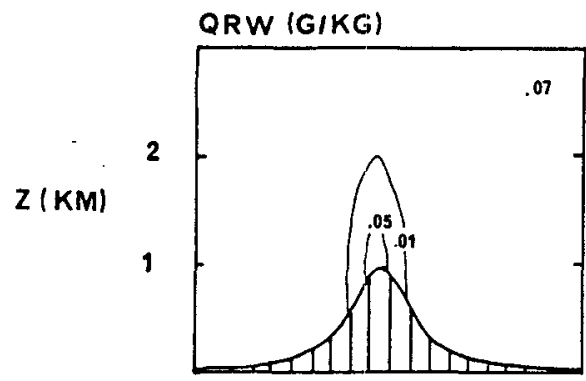

$P(M M / H)$

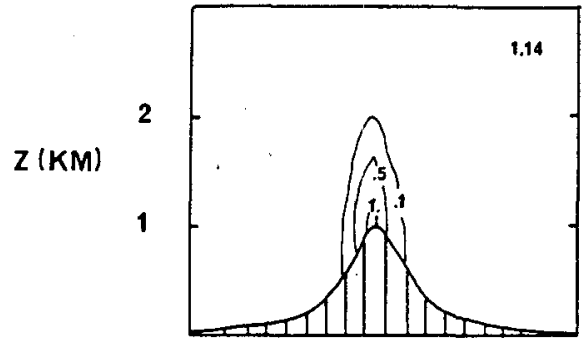

B.R. 1

QRW (GIKG)

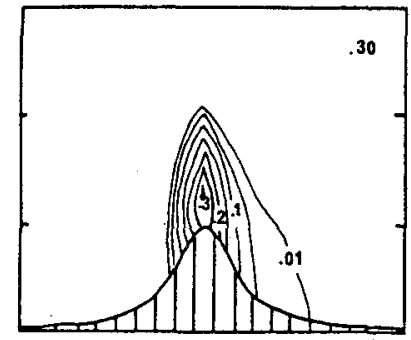

$P(M M / H)$

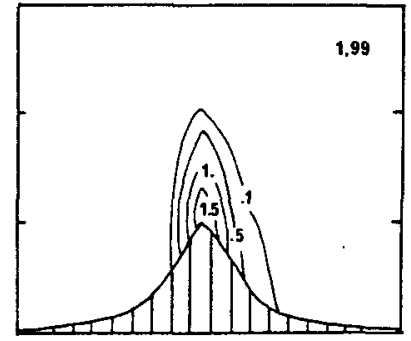

B.R. 2
QRW (G/KG)

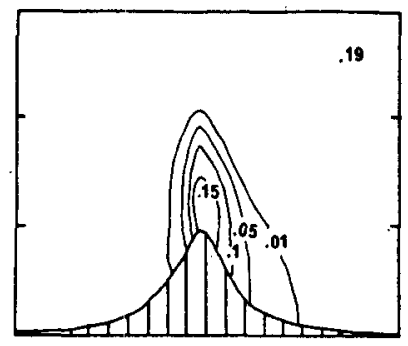

$P(M M / H)$

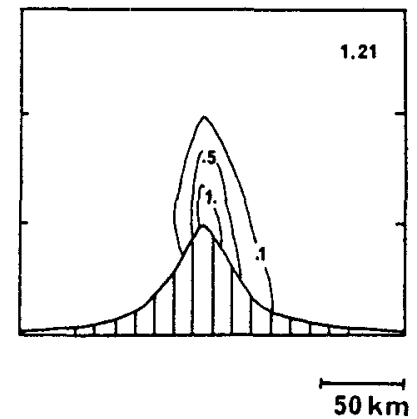

a

FIG. 10. As in Fig. 8 except for run C.

seemed that the orographic enhancement of rain through the feeder-seeder mechanism would provide an especially appropriate meteorological situation to test the capabilities of the two schemes to simulate the expected interactions between dynamics and microphysics.

\section{Feeder-seeder cloud simulations}

The mountain wave simulations give evidence of the main differences between $K$ and BR but do not enable us to draw any definitive conclusions in favor of one or the other parameterization. Therefore, it is worthwhile to check the results from the two schemes against experimental data. A field study of orographic rain conducted by Hill et al. (1981) over South Wales has been selected for several reasons. First, this experiment is well documented, combining radar measurements and rain gauge data. Results from these observations showed that the generation of orographic rain is greatly favored by the Bergeron (1965) feeder-seeder mechanism, according to which raindrops from upper level (seeder) clouds wash out small droplets through accretion within low-level (feeder) clouds formed over the hill. Finally, in a previous paper, Richard et al. (1987) have shown that their numerical model coupling dynamics with detailed microphysics gives better agreement with the observations than the simpler theoretical model of washout developed by Bader and Roach (1977) and rerun by Hill et al. (1981). In par- ticular, the numerical model (Richard et al. 1987) was able to reproduce the strong observed dependency of the precipitation enhancement upon the low-level windspeed. This dependency was underestimated by the theoretical model (Hill et al. 1981). Therefore, this dataset appears quite adequate for a comparative study between the two microphysical schemes of $K$ and BR.

We have simulated the 8 events presented by Hill et al. (1981). Some of the events were subdivided according to the low-level windspeed $v_{L}$, yielding a total of 14 cases. These cases are listed in Table 1 together

TABLE 1. Computed cases for the observations of Hill et al. (1981).

\begin{tabular}{cccc}
\hline \hline Case & $\begin{array}{c}v_{L} \\
\left(\mathrm{~m} \mathrm{~s}^{-1}\right)\end{array}$ & $\begin{array}{c}z_{s} \\
(\mathrm{~km})\end{array}$ & $\begin{array}{c}P_{s} \\
\left(\mathrm{~mm} \mathrm{~h}^{-1}\right)\end{array}$ \\
\hline 1 & 30 & 2.2 & 2.5 \\
2 & 28 & 1.5 & 1.5 \\
$3 \mathrm{a}$ & 23 & 1.5 & 1 \\
$3 \mathrm{~b}$ & 26 & 1.5 & 1 \\
$4 \mathrm{a}$ & 16 & 1.5 & 1 \\
$4 \mathrm{~b}$ & 22 & 1.5 & 1 \\
$4 \mathrm{c}$ & 26 & 1.5 & 1 \\
5 & 21 & 1.5 & 1 \\
$6 \mathrm{a}$ & 19 & 1.5 & 1 \\
$6 \mathrm{~b}$ & 17 & 1.5 & 1 \\
$7 \mathrm{a}$ & 14 & 1.5 & 1.5 \\
$7 \mathrm{~b}$ & 18 & 1.5 & 1.5 \\
$7 \mathrm{c}$ & 21 & 1.5 & 1.5 \\
8 & 14 & 1.5 & 3 \\
\hline
\end{tabular}


with the seeding height $z_{s}$ and the precipitation rate at seeding level $P_{s}$. Further details can be found in Richard et al. (1987). The model is initialized for each case with the corresponding radiosounding taken from Hill et al. (1981). The terrain is represented by a slope of 1 in 40 leading to a $400 \mathrm{~m}$ high plateau. The model is run over the 14 seeding events with $K, B R 1$ and BR2, defined exactly as for the mountain wave simulations. In each case, the orographic enhancement of the surface rainfall rate is computed as the difference between the precipitation rate at the hill crest, $P_{h}$, and the precipitation rate at the coast, $P_{0}$. Figure 11 presents the computed enhancements from coast to hill versus the
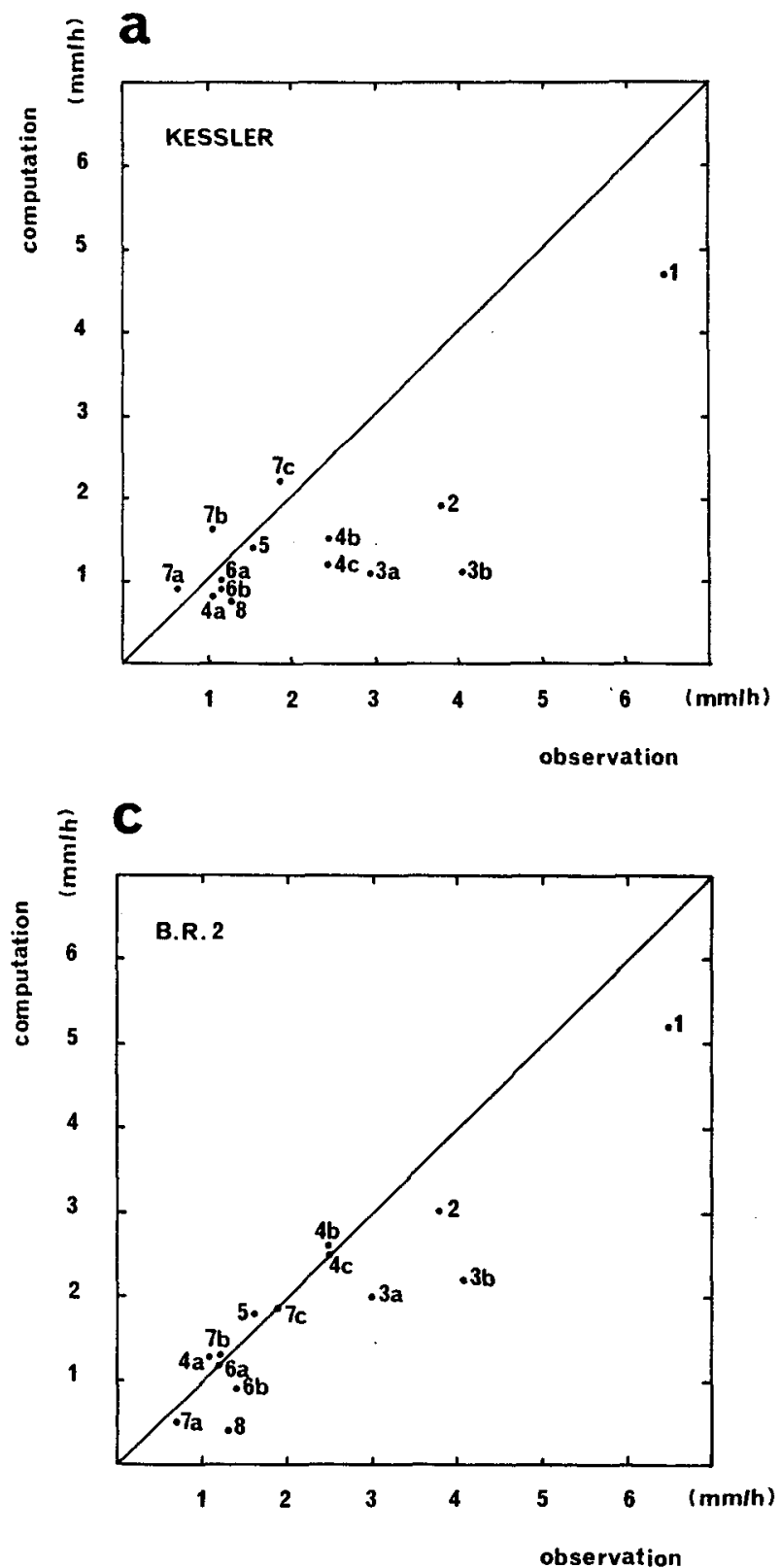

observed values for all cases. Figures $11 \mathrm{a}, 11 \mathrm{~b}$ and $11 \mathrm{c}$ correspond respectively to computations with the $K$, BR1 and BR2 parameterizations. The best agreement between computations and observations is found for the BR1 parameterization; BR2 does not give results as good as BR 1 and shows a slight tendency to underestimate the enhancement. In the case of the BR parameterizations, the best fit to the observed data is obtained for the most maritime case BR1. The agreement with observations was even better with a more maritime cloud spectrum $\left(\sigma_{c}=0.28 ; \overline{D_{c}}=40 \mu \mathrm{m}\right)$ as simulated in Richard et al. (1987); however, the difference between the two BR parameterizations is not as large as

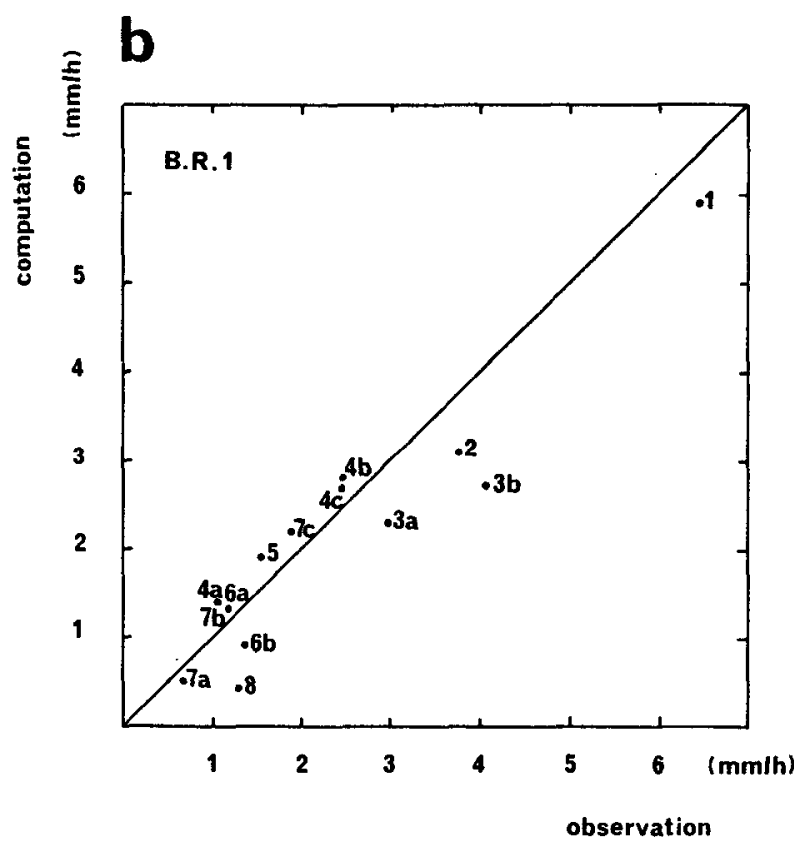

FIG. 11. Computed orographic enhancement $P_{h}-P_{0}$ versus the observed value for the fourteen cases of Hill et al. (1981). (a) for K, (b) for BR1 and (c) for BR2 parameterizations. 
the difference between the $\mathrm{K}$ and BR schemes. With Kessler, the enhancement is globally underpredicted, especially in the case of strong low-level windspeeds (cases 1, 2, 3, 4b and 4c). Figure 12 shows the precipitation enhancement as a function of the low-level windspeed for the observations and the three computations. All the parameterizations approximately depict the enhancement in the speed range of 10 to $20 \mathrm{~m} \mathrm{~s}^{-1}$. For stronger wind values, large discrepancies appear between observations and the Kessler results. Only the BR parameterizations are able to reproduce the observed dependency of the orographic enhancement on the low-level windspeed.

To investigate why the $\mathrm{K}, \mathrm{BR} 1$ and $\mathrm{BR} 2$ parameterizations behave differently in the simulation of these precipitation episodes, various microphysical fields are detailed for the case 2 sounding corresponding to a strong low-level windspeed. Figure 13 presents vertical cross sections of the cloud water mixing ratio, the rainwater mixing ratio and the precipitation rate for Kessler, BR1 and BR2. This figure has exactly the same format as Fig. 6, where the corresponding cloud and precipitation fields were shown for the mountain wave simulation. In that case, the cloud water mixing ratios were about the same in all three parameterizations. In the feeder-seeder cloud simulation, the Kessler cloud water mixing ratio is twice as large as the BR cloud water mixing ratios. This must be related to the effciency of the washout process which drives the feederseeder mechanism and is greater for the BR formulations than for the $\mathrm{K}$ scheme. For this simulation, raindrop concentrations around $100-200 \mathrm{~L}^{-1}$ have been

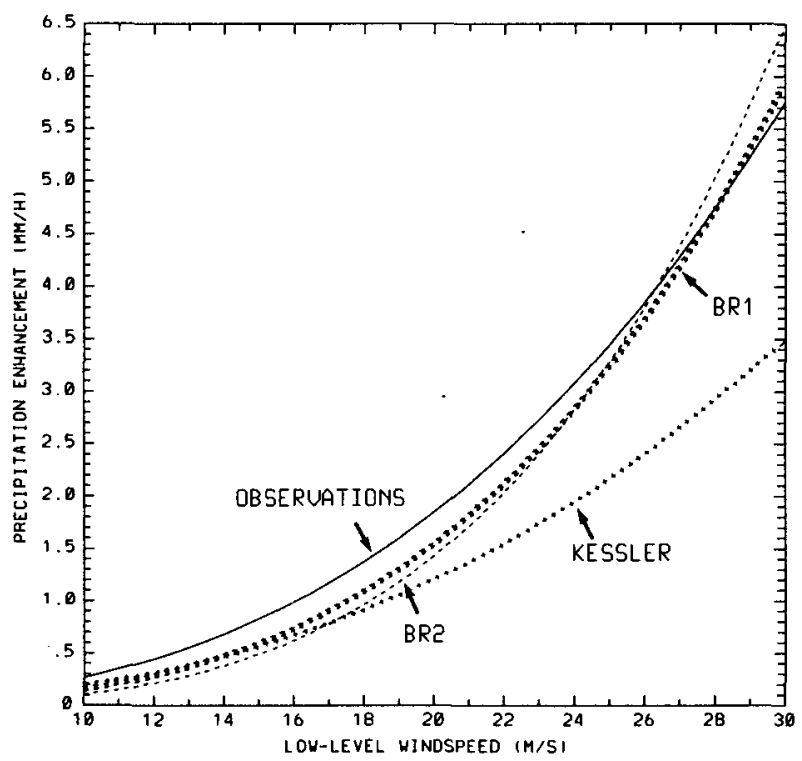

FIG. 12. Precipitation enhancement as a function of low-level windspeed for the observations and for the three computations with $\mathrm{K}, \mathrm{BR} 1$ and $\mathrm{BR} 2$. obtained using the BR parameterization. Recalling the discussion of Fig. 4, a high value of the raindrop concentration in BR leads to more efficient accretion rate than Kessler for a given rainwater mixing ratio. Another evidence of the efficiency of the washout process is in the location of the maxima in rainwater mixing ratios. In the $B R$ simulations, the maximum in the rainwater mixing ratio spreads below the seeding level down to the ground. In the Kessler case, the maximum rainwater mixing ratio is focussed over the crest of the hill near the ground, because seeding raindrops precipitate with larger terminal velocity and cannot grow as much by accretion as in the case of BR.

The precipitation rates reflect the rainwater fields. The value of the precipitation rate at the coast is lightly smaller for Kessler than for BR1 and BR2 while at the crest of the hill there is a much larger contrast between $\mathrm{K}$ and $\mathrm{BR}$. Looking at the horizontal extent of the cloud, the BR raindrops growing much more efficiently through accretion should increase the precipitation at the coast as well as at the hill crest. The efficiency of the Bergeron process in the case of BR cannot by itself explain the difference in the results at hill top. There is also a great distortion in the spatial distribution of the precipitation rate for $\mathrm{BR}$, which is not noticed for Kessler. This suggests, as for the mountain wave simulation, that wind drift effects are acting to displace the precipitation field downwind. A complementary sensitivity test has been performed with the case 2 simulation in which horizontal advection effects have been withdrawn in the rainwater prediction [Eqs. (2), (4) and (5)]. Results from this sensitivity study are shown in Fig. 14 with vertical cross sections of the precipitation rates with and without wind drift effects in the $K$ and BR 1 cases. For Kessler, with or without the advection effect, the precipitation patterns are not significantly modified either at the coast or at the crest of the hill. By way of contrast, the BR precipitation field is much less distorted and precipitation at the coast is enhanced when wind drift effects are suppressed. It should be noticed that without wind drift effects, rainfall at the crest does not correspond to a maximum as was previously the case.

In conclusion, it has been shown that the accretion process combined with the horizontal advection effects lead to different precipitation patterns for the $\mathrm{K}$ and BR schemes. This should account for the better agreement found between computations and observations in the BR simulation in the case of strong mean windspeed. In case of lighter low-level windspeed, vertical motions are weaker and smaller in area, less cloud water is available to be washed out by the rain and wind drift effects are negligible. Therefore, when the low-level wind speed ranges from 10 to $20 \mathrm{~m} \mathrm{~s}^{-1}$, there is a close agreement between observations and computations for the three parameterizations. Conversely, for windspeeds exceeding $20 \mathrm{~m} \mathrm{~s}^{-1}$ only the BR computations are in agreement with the observations. 

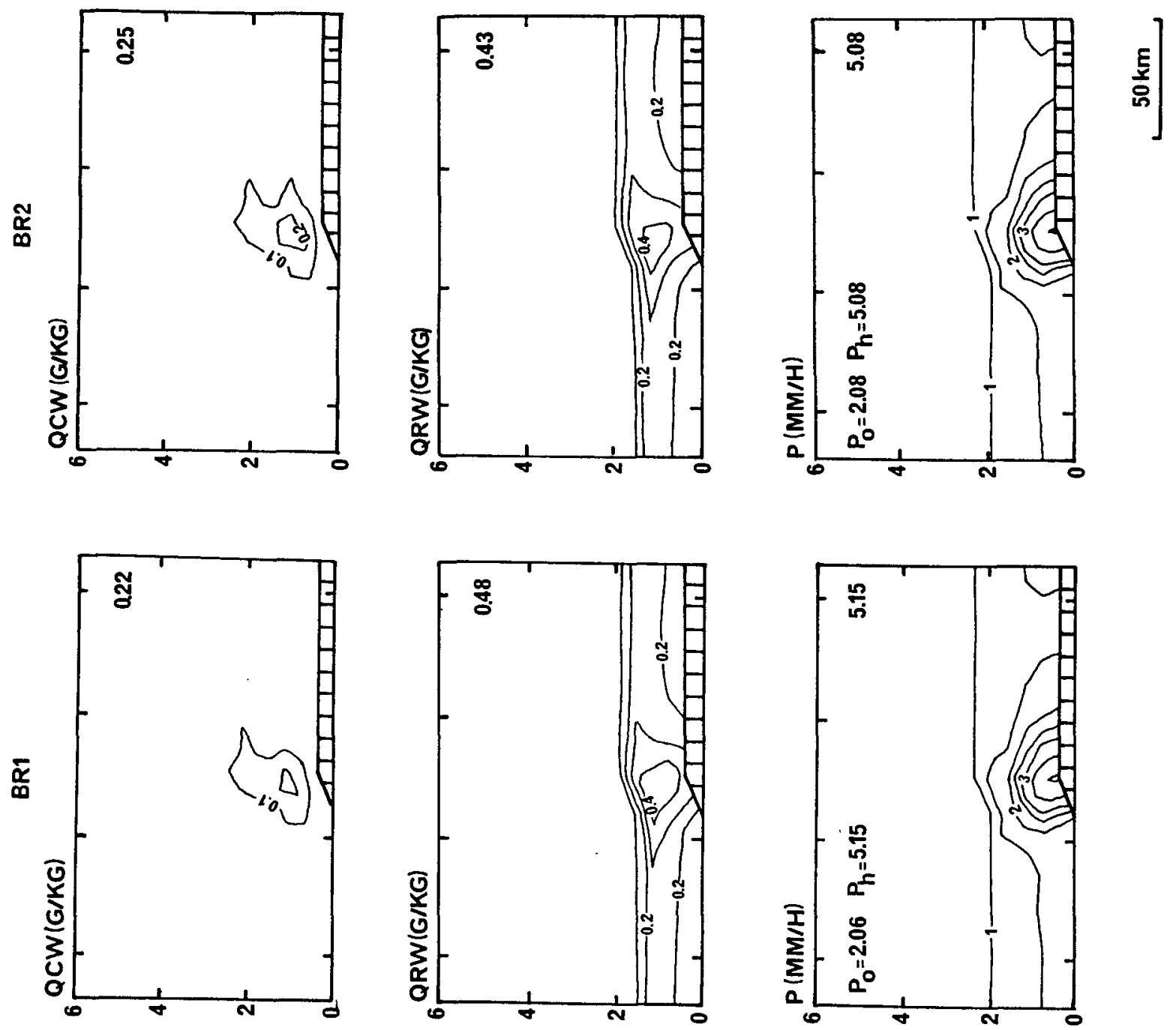

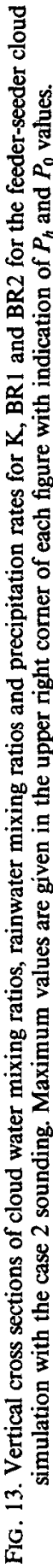
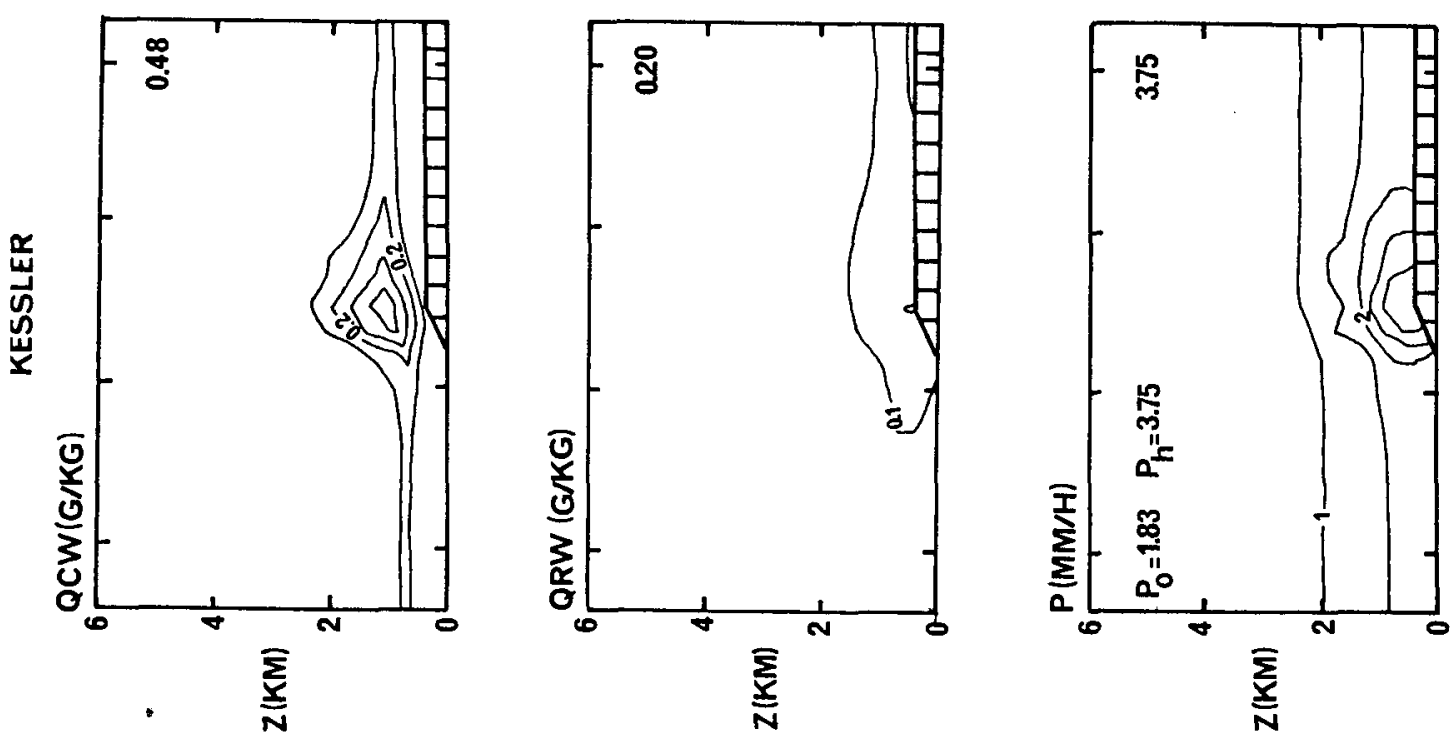
KESSLER

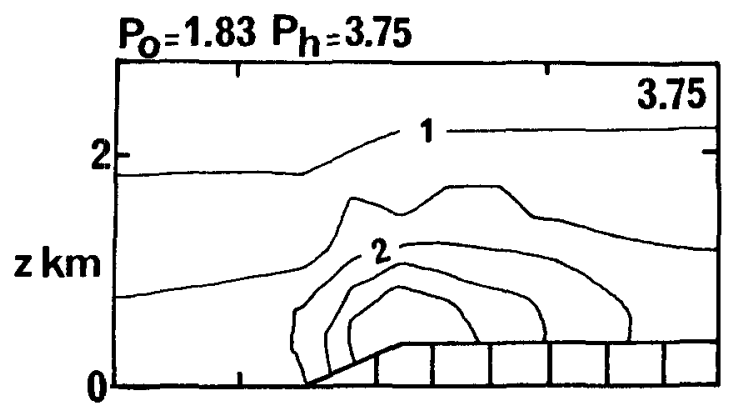

b)

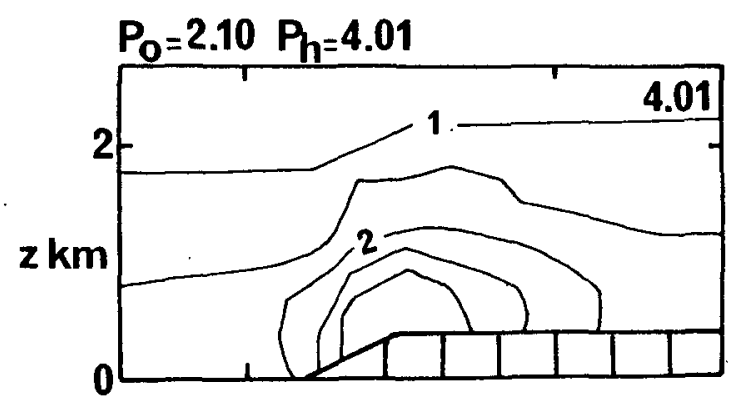

B.R.1
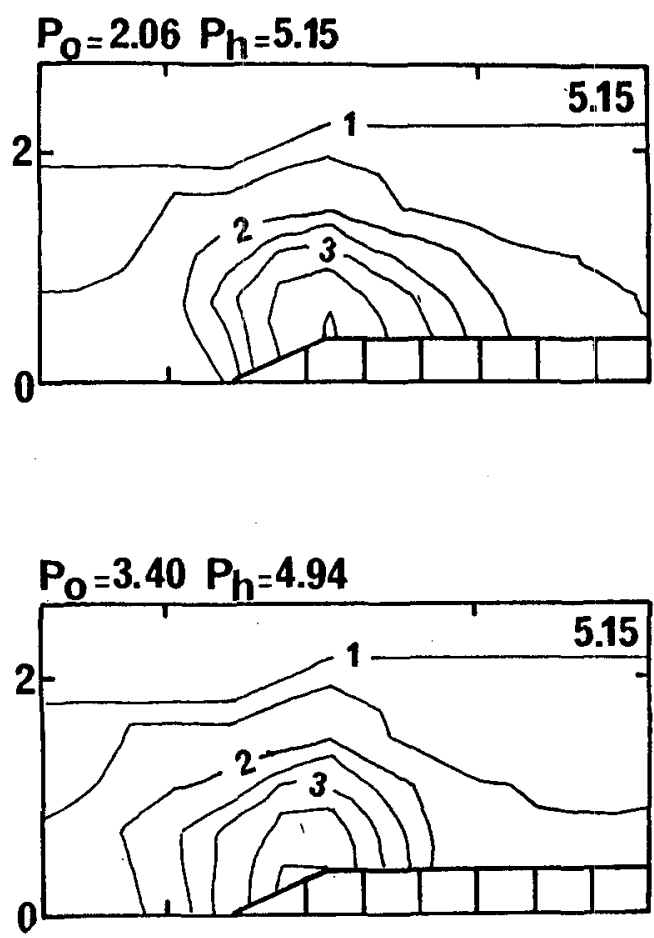

$50 \mathrm{~km}$

FIG. 14. Vertical cross sections of the precipitation rates with the case 2 sounding for $\mathrm{K}$ and BR1 parameterizations (a) including wind drift effects, (b) excluding wind drift effects. Maximum values are given in the upper right corner of each figure with indication of $P_{h}$ and $P_{0}$ values.

\section{Conclusion}

A complete description of the Berry and Reinhardt parameterization and of the Kessler parameterization has first of all displayed differences in raindrop size distributions and in microphysical rate expressions. The main conclusion of this detailed analysis is the greater flexibility of Berry and Reinhardt's scheme versus Kessler's formulation, due to an extra predictive equation of raindrop number concentration and to a somewhat less intuitive representation of some microphysical processes. For example, the Berry and Reinhardt autoconversion formula allows the model to respond to differing air masses and the Kessler parameterization does not take into account the decrease in the relative number of small drops due to evaporation.

Next, the two sets of microphysical parameterizations have been compared for various orographic situations in a meso $\beta$-scale model. Sensitivity tests with mountain wave simulations have first been performed to investigate the impact of the above differences on the predicted rainfall at the ground. In conditions of similar autoconversion rates, rainfall rates are comparable in intensity but their downwind spreading is markedly larger in the Berry and Reinhardt case than in the Kessler case. This comparative study has been pursued further using observed feeder-seeder cloud situations involving intricate microphysical processes. Berry and Reinhardt's parameterization led to a good agreement with the experimental data and was the only one capable of reproducing the observed dependency of the orographic rainfall rate enhancement upon the low-level windspeed.

In conclusion, recommendations in favor of one or the other rain parameterization for mesoscale modeling will depend on the problem to be addressed. The impact of the selected microphysical scheme is going to be different if one deals with either surface precipitation forecasting or chemical species evolution in cloud systems. The Berry and Reinhardt parameterization is probably more appropriate to wet chemistry studies since recent theoretical predictions from a sophisticated cloud model (Flossmann and Pruppacher 1988) and experimental observations (Noone et al. 1988) have suggested that rainwater chemical composition, e.g., rainwater $\mathrm{pH}$, depends on drop size. Regarding the large-scale precipitation forecast, the main difference between the two parameterizations results from the 
sensitivity of raindrops to wind drift effects. The two schemes will diverge more for strong wind situations or at meso $\gamma$-scale than for light wind situations or at meso $\alpha$-scale. It should be noted, however, that the Berry and Reinhardt parameterization does require the solution of an additional predictive equation, and hence additional memory. For computations on the meso $\alpha$-scale, especially when computational speed is a major concern such as in the production of operational forecasts, the Kessler parameterization may in fact be preferable.

Further investigations are needed to complete this study, which was restricted to orographic precipitation; the two schemes could for instance be tested for the case of frontal rain. The crucial role of evaporation and water loading effects in the dynamics of moist frontogenesis foreshadows differences in generation, location and intensity of the frontal rainbands.

Acknowledgments. The authors wish to thank Dr. E. C. Nickerson, Prof. R. Rosset and Dr. P. Mascart for their helpful comments and J. Duron for computing assistance. This work was supported by funds from Electricité de France. Computer resources were provided by ECMWF (Reading, England), CCVR (Palaiseau, France, project $\mathbf{n}^{\circ} 1717$ ) and Météorologie Nationale (Paris).

\section{APPENDIX}

\section{List of Principal Symbols}

a Kessler threshold value for autoconversion

$A_{3} \quad$ thermodynamical function $\left[=\frac{R T}{e_{s} D_{v}}+\frac{L_{v}}{k_{a} T}\right.$

$$
\left.\times\left(\frac{L_{v}}{R_{v} T}-1\right)\right]
$$

$D \quad$ drop diameter

$D_{g r} \quad$ predominant diameter of the rainwater lognormal distribution

$D_{0 c} \quad$ median size diameter for cloud droplet lognormal distribution

$D_{0 r} \quad$ median size diameter for raindrop log-normal distribution

$\overline{D_{c w}}$

cloud droplet mean diameter (defined by $\rho_{a} q_{c w}$ $=\frac{1}{6} N_{c w} \rho_{w} \pi \bar{D}_{c w}{ }^{3}$ )

$\overline{D_{r w}} \quad$ raindrop mean diameter (defined by $\rho_{a} q_{r w}$ $=\frac{1}{6} N_{r w} \rho_{w} \pi{\overline{D_{r w}}}^{3}$ )

$D_{v} \quad$ water vapor diffusivity

$e_{s} \quad$ partial pressure for saturating vapor

$F_{r}(Q)$ turbulent mixing term

$k_{a} \quad$ dry air thermal conductivity

$k_{1} \quad$ Kessler autoconversion coefficient

$L_{v} \quad$ latent heat of vaporization

$N_{0} \quad$ intercept parameter of the Marshall-Palmer distribution
$N_{c w} \quad$ cloud droplet total number concentration

$N_{r w} \quad$ raindrop total number concentration

$P \quad$ precipitation rate

$P_{0} \quad$ precipitation rate at the coast

$P_{h} \quad$ precipitation rate at the hill crest

$P_{s} \quad$ precipitation rate at the seeding level

$p \quad$ pressure

$p_{0} \quad$ reference pressure $(1000 \mathrm{mb})$

$q \quad$ sum of water vapor mixing ratio and cloud

water mixing ratio

water vapor mixing ratio

saturation vapor mixing ratio

cloud water mixing ratio

rainwater mixing ratio

universal gas constant

Reynolds number

gas constant for water vapor

temperature

reference temperature at $p_{0}$

relative variance of cloud spectrum

low-level windspeed

$v_{L}$

$V(D)$ terminal fall velocity for a drop of diameter $D$

seeding height

Berry and Reinhardt autoconversion coefficient

dynamical viscosity of air

slope parameter of the Marshall-Palmer distribution

air density

reference air density at $p_{0}$

density of water

standard geometric deviation for cloud lognormal spectrum

standard geometric deviation for rain lognormal spectrum

surface pressure

pressure coordinate defined by $\sigma=p / \pi$

vertical coordinate defined by $\sigma=\left(4 \nu-\nu^{4}\right) / 3$

\section{REFERENCES}

Bader, M. J., and W. T. Roach, 1977: Orographic rainfall in warm sectors of depressions. Quart. J. Roy. Meteor. Soc., 103, 269280.

Bergeron, T., 1965: On the low-level redistribution of atmospheric water caused by orography. Suppl. Proc. Int. Conf. Cloud Phys., Tokyo, 96-100.

Berry, E. X., 1967: Cloud droplet growth by collection. J. Atrnos. Sci., 24, 688-701.

- and M. P. Pranger, 1974: Equations for calculating the terminal velocities of water drops. J. Appl. Meteor., 13, 108-113.

—, and R. L. Reinhardt, 1974a: An analysis of cloud drop growth by collection: Part II. Single initial distributions. J. Atmos. Sci., 31, 1825-1831.

$\longrightarrow$, and - 1974b: An analysis of cloud drop growth by collection: Part III. Accretion and self-collection. J. Atmos. Sci., 31, 2118-2126.

Chaumerliac, N., E. Richard, J.-P. Pinty and E. C. Nickerson, 1987: Sulfur scavenging in a mesoscale model with quasi-spectral mi- 
crophysics: Two-dimensional results for continental and maritime clouds. J. Geophys. Res., 92, 3114-3126.

Clark, T. L., and W. D. Hall, 1983: A cloud physical parameterization method using movable basis functions: Stochastic coalescence parcel calculations. J. Atmos. Sci., 40, 1709-1728.

Cotton, W. R., 1972: Numerical simulation of precipitation development in supercooled cumuli. Mon. Wea. Rev., 100, 757-784.

Davies, H. C., 1983: Limitations of some common lateral boundary schemes used in regional NWP models. Mon. Wea. Rev., 111, $1002-1012$.

Durran, D. R., and J. B. Klemp, 1983: A compressible model for the simulation of moist mountain waves. Mon. Wea. Rev., 111, 2341-2361.

Feingold, G., and Z. Levin, 1986: The lognormal fit to raindrop spectra from frontal convective clouds in Israel. J. Climate Appl. Meteor., 25, 1346-1363.

Flossmann, A. I., and H. R. Pruppacher, 1988: A theoretical study of the wet removal of atmospheric pollutants. Part III: The uptake, redistribution, and deposition of $\left(\mathrm{NH}_{4}\right)_{2} \mathrm{SO}_{4}$ particles by a convective cloud using a two-dimensional cloud dynamics model. J. Atmos. Sci., 45, 1857-1871.

Gunn, R., and G. D. Kinzer, 1949: The terminal velocity of fall for water droplets in stagnant air. J. Meteor., 6, 243-248.

Hill, F. F., K. A. Browning and M. J. Bader, 1981: Radar and raingauge observations of orographic rain over south Wales. Quart. J. Roy. Meteor. Soc., 107, 643-670.

Hsie, E. Y., R. A. Anthes and D. Keyser, 1984: Numerical simulation of frontogenesis in a moist atmosphere. J. Atmos. Sci., 41, 25812594.

Kessler, E., 1969: On the distribution and continuity of water substance in atmospheric circulations. Meteor. Monogr., 10, No. 32, Amer. Meteor. Soc., 84 pp.
Marshall, J. S., and W. M. Palmer, 1948: The distribution of raindrops with size. J. Meteor., 5, 165-166.

Nickerson, E. C., E. Richard, R. Rosset and D. R. Smith, 1986: The numerical simulation of clouds, rain and airflow over the Vosges and Black Forest Mountain: A meso- $\beta$ model with parameterized microphysics. Mon. Wea. Rev., 114, 398-414.

Noone, K. J., R. J. Charlson, D. S. Covert, J. A. Ogren and J. Heintzenberg, 1988: Cloud droplets: Solute concentration is size dependent. J. Geophys. Res., 93, 9477-9482.

O'Brien, J. J., 1970: A note on the vertical structure of the eddy exchange coefficient in the planetary boundary layer. J. Atmos. Sci., 27, 1213-1215.

Orville, H. D., and F. J. Kopp, 1977: Numerical simulation of the life history of a hailstorm. J. Atmos. Sci., 34, 1596-1618.

Pruppacher, H. R., and J. D. Klett, 1978: Microphysics of Clouds and Precipitation. D. Reidel, $714 \mathrm{pp}$.

Richard, E., N. Chaumerliac, J. F. Mahfouf and E. C. Nickerson, 1987: Numerical simulation of orographic enhancement of rain with a mesoscale model. J. Climate Appl. Meteor., 26, 661-669.

Rutledge, S. A., and P. V. Hobbs, 1983: The mesoscale and microscale structure and organization of clouds and precipitation in midlatitude cyclones. Part VIII: A model for the "seeder-feeder" process in warm-frontal rainbands. J. Atmos. Sci., 40, 11851206.

Waldvogel, A., 1974: The No. jump of raindrop spectra. J. Aimos. Sci., 31, 1067-1078.

Zhang, D.-L., E.-Y. Hsie and M. W. Moncrieff, 1988: A comparison of explicit and implicit predictions of convective and stratiform weather systems with a meso- $\beta$-scale numerical model, Quart. J. Roy. Meteor. Soc., 114, 31-60. 